\title{
Applications Of Blockchain Technology In Smart City Development
}

\author{
Sonali Karale, Vishal Ranaware
}

\begin{abstract}
In 2016, India launched the smart cities mission. The objective of this mission is to developed cities by using 'Smart' solutions that provide core infrastructure and give citizens a decent quality of life, a clean and sustainable environment. The focus is on sustainable and inclusive development. To achieve this it uses the technology to integrate and manage the infrastructures to provide better services and ensure efficient and optimal utilisation of available resources. Incorporation of new technologies for the development of smart cities gives the new ways of rethinking different services. In this paper, we are going study the applications of blockchain technology in smart city development.
\end{abstract}

Keywords : Assets, Blockchain Technology, Security, Smart Contracts

\section{INTRODUCTION}

In recent decades, the rapid growth of urbanization gives a significant advancements in developing efficient, intelligent and sustainable solutions. Smart city needs these solutions in providing better management of waste, water, energy, mobility and various e-governance services. Smart cities are focusing on the use of modern technologies like IoT, Big Data, Artificial Intelligence, Machine Learning, etc aiming to create more liveable urban environment by utilising resources optimally and reduce the cost. The features of a smart city are defined by the Government and many of them can be implemented using blockchain technology result in more transparent, immutable and secure solutions [1]. This paper focuses on the adoption of a blockchain-based solution and its applications in the smart city development.

\section{PRIOR WORK}

Finding new applications for Blockchain has naturally connected the technology to the emerging field of Smart Cities [2], [3]. As both fields are very promising researchers are looking into everything from Smart Roads [4] to Smart Contracts [5] and the future of banking and healthcare [6], [7].

Extensive research is being conducted into security issues related to Blockchain [8] resolving issues identified in existing instances [9] or preventing the appearance of others well before the systems that would be vulnerable to them even come into existence [10]. There are already a number of large scale implementations in Smart Cities. China has taken huge steps towards developing Blockchain-based solutions for its Smart Cities [11]. Dubai is turning towards

Revised Manuscript Received on September 14, 2019.

Sonali Karale, Academics Department, Symbiosis Centre for Distance Learning, Pune, Maharashtra, India, (Email: karalesonali@gmail.com)

Vishal Ranaware, Academics Department, Symbiosis Centre for Distance Learning, Pune, Maharashtra, India (Email: adv.vishalranaware@gmail.com)
Blockchain to keep its competitive edge in business by exploring the concept of e-Democracy [12]. In a similar way, applications in voting technology [13] and legal support systems have a huge impact on future Smart Cities. Integration of blockchain technology with devices in a smart city will create a common platform where all devices would be able to communicate securely in a distributed environment [8].

\section{BLOCKCHAIN TECHNOLOGY}

Blockchain is a peer-to-peer distributed ledger technology which records transactions, agreements, contracts, and sales [14]. It also validate transactions in order to create a verified and unalterable ledger of information. The features of open, transparent, interconnection and peer-to-peer, storage and sharing in the Blockchain are relevant to the openness, interconnection, peer-to-peer and Shared characteristics of the energy Internet [15].

A blockchain has two types, i.e. public or private. The essential difference between a public and private blockchain is that one operates in a decentralised open environment where there are no restrictions on the number of people joining the network, while the other operates within the confines defined by a controlling entity. Following figure shows the detailed working of blockchain [1]:

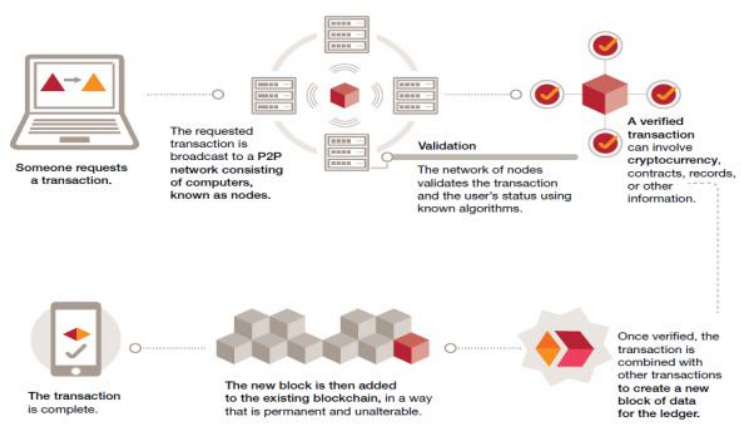

Fig. 1: Working of Blockchain

\section{APPLICATIONS OF BLOCKCHAIN \& RESULTS}

\section{A. Secure Data Communication}

A blockchain based security framework is proposed in [8], to enable secure data communication in a smart city. Blockchain technology provides many unique features like help in improving reliability, scalability, support faster and efficient operation with fault tolerance capability and it is

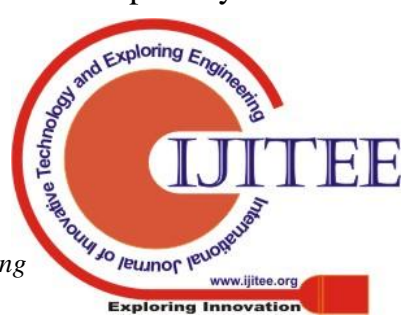


resilient against many threats.

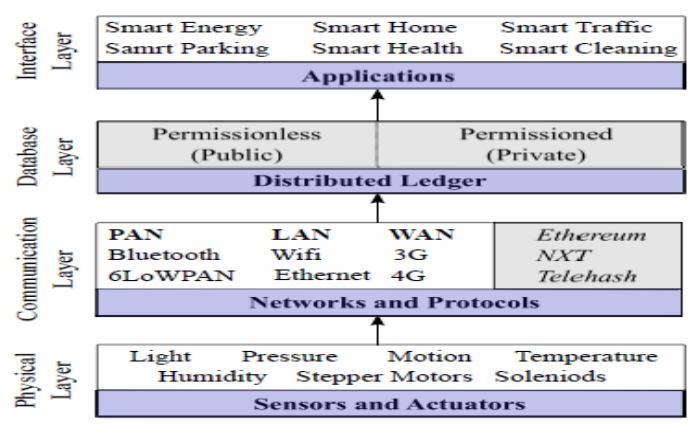

Fig.2: Smart city security framework

\section{B. Smart Contracts}

A smart contract is intended to digitally perform the transaction between the parties without third party involvement. These transactions are trackable and irreversible, and be able to verify the performance of transaction and negotiate, if required. Smart contracts are useful for all sort of situations including the financial and legal processes like property law, financial services, crowd funding agreements and insurance premiums.

Blockchain technology is used to develop a stronger and accessible contracts, only the parties who are involved in the contract could hold the actual knowledge of it but the authenticity of the same could be verified by the third party by using the general security measures including hashed crypto keys (USA Patent No. 15/594,364, 2017). Ethereum as well as Solidity are the most commonly used for smart contract development. In some countries, the use of Blockchain-certified contracts would bring an additional reduction in cost associated with the use of notaries, another branch of the legal profession that adds costly overheads to current contracting practices. Securing contracts using Blockchain is not just viable replacement for the use of notaries, it would also mean an improvement in speed, convenience and reliability of the certification process [16].

\section{Citizen Participation:}

Citizen's contribution is very important in the planning and development of smart city. With blockchain we can developed a platform called as blockchain-based loyalty and rewards platform which ensures that the right contributors from the society are get rewarded for their contribution in the smart city development.

We can also use blockchain-based voting platforms which is decentralised and more secure, provide a unique voting system by removing the complexities and inefficiencies of the other forms of voting.

By using such platforms, citizens can provide their feedback, also raise the grievances which can be considered and resolved. This whole process nothing but improve the smart city facilities.

\section{Economy and Employment}

The blockchain technology can useful in local business registration procedures from inception to dissolution. It also gives a clear picture to all the interested parties, helps in reducing the cost of doing business and increase the ease. It also help in setting up the business and resolving the issues faster as compare to the traditional method. But to implement this a long run benefits, we need to integrate it with the centralised corporate registry.

To have a transparent logistics management solution we need to remove the unwanted layers of verification which act as a barrier in creating an efficient sustainable value chain. Blockchain-based logistics (and finance) management solutions nothing but help us in removing these barriers and help in creating a better logistics management solution.

Similarly we also use a blockchain-based employment register for employees. It is transparent, secure and keep the employment history. This is helpful for the citizens before assigning any work to the employee by obtaining information about him/her and their service/s (like plumbing, etc.) quality. This is one of the trusted system to be implemented.

\section{E. Health}

Using blockchain technology, we can create a single electronic health record for the citizens. It is more flexible, secure and trustworthy for the patients as well as health providers. Such records are decentralised and patients no need to carry multiple health records with them while visiting the consultant. They are made available at any time. We can also register the practitioners and facilities of care providers. It ensure better control on medical service providers in the city as well as on the authorised practitioners. We can also create a transparent pharmaceutical supply chains using blockchain. By using smart contract our work of insurance claims approval and settlement becomes easier.

\section{F. Education}

Blockchain technology is also helpful in education sector, where we can keep the educational records of the student's credentials securely and shared them with the stakeholder's through proper consent mechanism. It also reduce the need of attestation as the records are available at any time and valid.

We also need to provide grant to the relevant children for their overall development. By using blockchain we can manage the grant system which ensures that the right child will receive the right grant at right time. Also the changes are done transparently. Such system helps in increasing the trust of citizens on the services.

\section{G. Property Registration/Auction}

We use a digitised/automate system for property registration, but it is time consuming, costly and also have many problems associated with tenuous land titles. Such problems can be eliminated if we use a blockchain for property registration, it reduce the cost, time and increased accuracy in record keeping. In this system, we can record all approvals, inspection reports and other related documents/certificates of the land/property. Such systems increase the trust and help in improving the economy by providing an immutable 30 -degree view of the asset. 
By using smart contracts we can validate the identity of the citizens. This validation process help us in allocating the houses to the right/respective citizens. Such system is transparent and openly auditable, improve the trust in the auction/allocation process.

\section{H. Renewable Energy}

Renewable energy is one of the prime sector where we can use the blockchain based system. They can help accelerate the enforcement of real-time differential pricing models to contain energy usage. Such models can promote local self-dependency on energy. It can also help in managing the power supply and balanced the load. We can also keep the records of the energy consumption and accordingly billing is generated. Citizens can invest in micro renewable energy farms, use the amount of energy required for day to day activity and excess energy sell back to the grid.

\section{Waste and Sanitation}

One of the major challenge in the development of smart city is the management of waste and sanitation. To deal with this challenge, we need to have efficient and better waste management strategies to accurately track the waste production level or disbursal. We can implement such a strategy by combining IoT-based solution with blockchain technology. Such systems also helpful in charging the penalties or rewards to the waste management companies if they fail to provide better time based services.

\section{J. Safety}

It is possible that the evidences produced to the court are altered and not identical to the real event. This nothing but delayed the processing of cases in the courts and increase the burden on the law enforcement agencies. Such evidences are cryptographically and unambiguously verify using blockchain based system to ensure that the evidences produced in the court are exactly identical to the actual event, not altered or modified. In this system, we need to register immutably all associated evidences of a case. It support faster processing of cases in the courts and minimise the tampering of evidences.

As we already discussed, blockchain technology provides end-to-end privacy and encryption which helps in keeping the information to be secured [17]. Encryption is one of the trusted method of securing the information using public and private keys.

We can also use blockchain based digitised system for the birth and death registration. This ensures that the records are accurate, complete, uniform and follow the timeline.

\section{K. $\quad$ Smart Assets}

The idea itself has evolved [20] incorporating Blockchain as a solution for cloud-based tracking of Smart Assets. Products and their individual components would be permanently monitored along the supply chain by updating a predefined set of characteristics thus providing information to distribution systems about their availability in real time. Better information means increased availability and optimized transport of items to where they are needed.

The Smart Asset model is particularly well adapted to merchandise storage and distribution, and storage tends to increasingly take place outside of cities. Increasing efficiency in distribution by turning itemized products into Smart Assets should have a tremendous effect on the use of space in the city. Less space will be required for storage in the city as inventory management and storage could one day switch completely from Just In Case (JIC) to Just-In-Time (JIT). As more space is made available by optimizing distribution we can expect Smart Cities to benefit from more diversity of products, more availability of green space, or new innovative functions for old storage spaces.

\section{CONCLUSION}

Blockchain technology has enormous potential when it comes technology has enormous potential when it comes to shaping the enhanced Smart Communities of the future in ways that are more efficient and provide better quality of living. For technology to deliver on its promise it must be allowed to change the status quo. Blockchain technology can provide a solution to a wide variety of problems which are generally faced by the smart cities. But the implementation of this technology in practice will depend on the administration and preferences of the community.

\section{REFERENCES}

1. Blockchain: The next innovation to make our cities smarter, PricewaterhouseCoopers Private Limited India, Jan. 2018, doi http://ficci.in/spdocument/22934/Blockchain.pdf

2. Sun, J., Yan, J., Zhang, K. Z., "Blockchain-based sharing services: What blockchain technology can contribute to smart cities?" Financial Innovation, 2016, vol. 2, issue 1, pp. 26.

3. Ibba, S., Pinna, A., Seu, M., Pani, F. E., "CitySense: blockchain-oriented smart cities", 2017, in Proc. of the XP2017 Scientific Workshops, ACM, pp. 12.

4. Sharma, P. K., Moon, S. Y., Park, J. H., "Block-VN: A Distributed Blockchain Based Vehicular Network Architecture in Smart City", Journal of information processing systems, 2017, vol.13, issue 1, pp. 184-195.

5. Watanabe, H., Fujimura, S., Nakadaira, A., Miyazaki, Y., Akutsu, A., Kishigami, J., "Blockchain contract: Securing a blockchain applied to smart contracts", in 2016 IEEE International Conference in Consumer Electronics (ICCE), pp. 467-468.

6. Peters, G. W., Panayi, E., "Understanding modern banking ledgers through blockchain technologies: Future of transaction processing and smart contracts on the internet of money", Banking Beyond Banks and Money, pp. 239-278.

7. Linn, L., M., K., "Blockchain for health data and its potential use in health it and health care related research", Use of Blockchain for Healthcare and Research Workshop in 2016

8. Biswas, K., Muthukkumarasamy, V., "Securing Smart Cities Using Blockchain Technology", in 2016 IEEE 14th International Conference on Smart Cities, pp. 13921393.

9. Luu, L., Chu, D.-H., Olickel, H., Saxena, P., Hobor, A. "Making smart contracts smarter", in Proc. ACM SIGSAC Conference on Computer and Communications Security, 2016, pp. 254-269. 
10. Kshetri, N. "Can Blockchain Strengthen the Internet of Things?" in IEEE IT Professional, 2017, vol.19, issue 4, pp. 68-72

11. Guo, M., Liu, Y., Yu, H., Hu, B., Sang, Z., “An overview of smart city in China", China Communications, 2016, vol.13, issue.5.

12. Karmakar, A., Sahib, U., "SMART DUBAI: Accelerating Innovation and Leapfrogging EDemocracy", "E-Democracy for Smart Cities" Singapore: Springer, 2017, pp. 197-257

13. Davidson, S., De Filippi, P., Potts, J., "Economics of blockchain", 2016, Available: https://hal.archivesouvertes.fr/hal-01382002/document

14. K. Christidis and M. Devetsikiotis, "Blockchains and Smart Contracts for the IoTs", IEEE Access, Special section on the plethora of Research in IoT, 2016, pp. 2292-2303

15. Shuling Li, "Application of Blockchain Technology in Smart City Infrastructure", IEEE International Conference on Smart Internet of Things (SmartIoT), 2018, vol. 1, pp.276-2766.

16. Christian Nãsulea, Stelian-Mihai Mic (2018). "Using Blockchain as a Platform for Smart Cities" Journal of $E$ - Technology, vol. 9 no. 2.

17. Barzilay, O. (2017). " 3 ways blockchain is revolutionizing cybersecurity". Forbes. Available: https://www.forbes.com/sites/omribarzilay/2017/08/21/3ways-blockchain-is-revolutionizingcybersecurity/\#5e4b25f82334

\section{AUTHORS PROFILE}

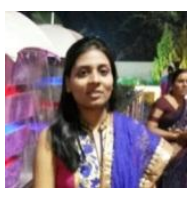

Sonali Karale, has completed her Masters in Computer Applications. She has rich experience in teaching at Post Graduate level. She has published various research papers in International and National Conferences. Her research area blockchain, video summerisation.

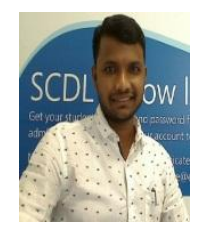

Vishal Ranaware, has completed his Master of Laws with specialization in Business Law \& Criminal Law from University of Pune. He has rich experience in teaching at Graduate and Post Graduate level. He has published various research papers in International and National Conferences. His research areas are company law, contract law, medical jurisprudence. 